\title{
Um estudo sobre o perfil do administrador através da teoria das inteligências múltiplas em amostras pareadas
}

\begin{abstract}
Sefisa Bezerra ${ }^{\mathrm{a}}$, Levi Leonido ${ }^{\mathrm{b}}$, Elsa Morgado ${ }^{\mathrm{c}}$, Mário Cardoso $^{\mathrm{d}}$, André Aragão ${ }^{\mathrm{e}}$
${ }^{\mathrm{a}}$ Universidade Estatual do Vale do Acaraú, Sobral, Brasil, sefisaquixada@gmail.com, ${ }^{\mathrm{b}}$ Universidade de Trás-os-Montes e Alto Douro, Vila Real, Portugal. Universiade Católica Portuguesa (CITAR), Porto, Portugal, levileon@utad.pt, ${ }^{\mathrm{c}}$ UTAD, Centro de Estudos Filosóficos e Humanísticos da Universidade Católica - Braga, Portugal, levielsa@utad.pt, ${ }^{\mathrm{d}}$ Instituto Politécnico de Bragança, Bragança, Portugal, cardoso@ipb.pt, e Instituto Federal do Piau,Cocal,Brasil, luisandrearagao@yahoo.com.br
\end{abstract}

\begin{abstract}
Resumo
Esse estudo pretende reconhecer e analisar o perfil do estudante do curso de Administração de uma Universidade pública localizada no Estado do CearáBrasil e o desenvolvimento das suas inteligências múltiplas, principalmente as interpessoal e intrapessoal, no decorrer do tempo. Trata-se da confrontação dos resultados desse mesmo estudo (parte da tese da autora) realizado no início do ano de 2015, sendo portanto, um estudo quantitativo, de campo, longitudinal, com amostras pareadas de $30 \%$ da quantidade da turma que iniciou em janeiro daquele ano. No que concerne ao tratamento e análise dos dados recolhidos foram privilegiados procedimentos estatísticos através da utilização do software estatístico SPSS (Statistical Package for the Social Science), utilizando também os dados da pesquisa anterior e fazendo um estudo comparativo antes-depois ou seja, amostras pareadas. A reaplicação da pesquisa permitiu verificar o crescimento e desenvolvimento das inteligências dos alunos no decorrer do curso e, paralelamente, consolidou a atuação da universidade como locus do saber, mantendo-se sempre que considerar a necessidade de melhoria contínua e da busca de novos métodos de aprendizagem.
\end{abstract}

Palavras chave: Inteligências Múltiplas, administração,aprendizagem 
Um estudo sobre o perfil do administrador através da teoria das inteligências múltiplas em amostras pareadas

\begin{abstract}
This study aims to recognize and analyze the profile of the student of the administration course of the Vale do Acarau State University in the State of Ceará-Brazil and the development of their multiple intelligences, especially the interpersonal and intrapersonal, over time. This is a comparison of the results of this same study (part of the author's thesis), carried out at the beginning of the year 2015, and therefore, a quantitative, field, longitudinal study with paired samples of $30 \%$ of the class january of that year. Regarding the treatment and analysis of the collected data, statistical procedures were favored using the statistical software SPSS (Statistical Package for the Social Science), also using the data of the previous research and doing a comparative study before-after, that is, paired samples. The reapplication of the research allowed to verify the growth and development of the intelligences of the students during the course and, at the same time, consolidated the performance of the university as locus of knowledge, maintaining whenever it considers the need for continuous improvement and the search of new learning methods.
\end{abstract}

Keywords: Multiple Intelligences, administration, learning

\title{
1. Introdução
}

As universidades são reconhecidas e respeitadas, como centros de formação e difusão do saber e de conhecimentos específicos, importante lócus de progresso para as ciências e para o momento histórico de cada sociedade. Acrescentando-se a preocupação e a reflexão do papel do indivíduo nesse contexto, vemos a iminente necessidade de estudar o seu agir e repensar suas atitudes e formas de conduzir as organizações, sejam públicas ou privadas, com mais responsabilidade e preocupação humana, consigo e com os outros que convivem e vivem sob os efeitos de suas tomadas de decisões. Conforme Demo (2009, p. 3) "a Universidade ocupa papel de absoluto destaque, desde que não se reduza a reproduzir conhecimento e que tem duas funções centrais hoje: reconstruir conhecimento e educar novas gerações". Ele também afirmou que "aprender é constituir um sujeito capaz de história própria, apresentando ainda outras marcas centrais, com destaque para a questão emocional e das inteligências múltiplas" (Demo, 2009, p.7). Fazendo um estudo mais concentrado nas ciências sociais, especificamente no curso de Administração, lócus da pesquisa, partimos na busca do entendimento e do reconhecimento da participação do papel da universidade na formação do indivíduo/estudante do curso citado, se há melhoria referencial em seu perfil e levantamos a seguinte reflexão:como evoluem as inteligências dos alunos no decorrer do tempo a partir dos diversos saberes que tiveram acesso e pelo 
qual foram apresentados, conduzidos e avaliados processualmente a partir de várias metodologias e olhares?

Esse estudo pretende reconhecer e analisar o perfil do estudante do curso de administração de uma universidade estadual pública no Estado do Ceará-Brasil e o desenvolvimento das suas inteligências múltiplas, principalmente as interpessoal e intrapessoal, no decorrer do tempo, a partir da confrontação dos resultados desse mesmo estudo realizado no início do ano de 2015.

O compromisso com uma formação acadêmica de qualidade, ética e cidadã deve fazer o estudante desenvolver-se (competência formal) sendo conhecedor da existência dos vários saberes proporcionados pela aprendizagem formal, pela pesquisa e pela extensão e, principalmente que ele será um alavancador de resultados visíveis através da criação e gestão de organizações que, consequentemente gerarão empregos e melhores condições de vida à população. Percebemos a constante criação de instrumentos legais, que a priori deveriam ser básicos para todo indivíduo, cito estatutos diversos, como dos direitos humanos, cartilhas contra assédio moral, manuais de sustentabilidade, dentre outros, e pensamos como a formação docente poderia ser mais incisiva nessas questões simplesmente "humanas": como agir perante as dificuldades diárias, as tomadas de decisão, a uso consciente de recursos, a objetivos de vida e de trabalho mais felizes e exequíveis, como à ele (estudante) sejam possibilitados mecanismos de aprendizagem para que se repense sua condição humana para então melhor lidar com outros indivíduos, grupos e organizações.

Segundo Tavares Filho e Bernardes $(2005$, p. 4) a universidade deve estar "dirigida ao perfil gerencial do administrador do futuro, que deve possuir algumas posturas indispensáveis como: iniciativa de ação e decisão, capacidade de negociação, de trabalhar em grupo, competência e autonomia para criar e inovar, capacidade de comunicação interpessoal, comprometimento com princípios éticos e capacidade de trabalhar em grupo".

O presente estudo trouxe-nos uma reflexão sobre como estamos vinculando a metodologia empregada à matriz curricular dos graduandos em Administraçãoe se esta possibilitará uma formação mais humana, lhe proporcionando um melhor desenvolvimento comportamental, ao lidarmos com as inteligências pessoais, o que acarretará, a médio prazo, quiçá, sociedades menos injustas e desiguais, visto o papel social desse profissional.

\section{Enquadramento}

Especificamos o curso de Administração e a partir do que afirmou Rosário (2010, p.4) “um curso na área de administração deve ter dinamicidade e ser ajustado ao ambiente, pois o administrador, além de trabalhar com as mudanças ambientais e de identificar novas 
Um estudo sobre o perfil do administrador através da teoria das inteligências múltiplas em amostras pareadas

tendências, deve atuar como agente de transformação". Trata-se de um curso classificado como das ciências sociais aplicadas com forte interdisciplinaridade com as ciências humanas. É também um curso pragmático, com muitas regras, com muito material instrumental na tentativa de subsidiar a solução de problemas reais e no Brasil.

O curso de Administração é um curso de Bacharelado e na universidade estudada existe à vinte e três anos, onde é regulamentado e reconhecido através do Sistema Nacional de Educação, tem muita importância para a região visto sua missão de formação para gestão regional/local e para o empreendedorismo. Suas unidades curricular estão assim dispostas no Plano Pedagógico: de formação profíssional 58\%, de formação básica e instrumental $25 \%$, de estudos quantitativos e suas tecnologias $8 \%$ e de formação complementar $9 \%$, distribuídos em nove semestres. Dessas unidades, muito poucas tem foco na área humana $\mathrm{e}$ nenhuma especificamente no desenvolvimento de inteligências, embora seja um curso interdisciplinar.

Desde 1996 os órgãos de classe nacionais responsáveis pela formação acadêmica do administrador têm feito estudos com caráter avaliativo com todas as instituições de ensino superior nacionais sobre como melhor desenvolver o curso e a definição e composição do perfil do administrador. Segundo Siqueira (1998) referido por Andrade e Amboni (2004, p. 56), "melhorando o ensino, teremos profissionais mais bem preparados, organizações bem administradas e, é claro, uma sociedade mais justa". E em 2005, foi definido pela Associação Nacional dos Cursos de Graduação em Administração (ANGRAD) e o Conselho Federal de Administração (CFA), as principais funções do administrador, nas quais resumimos as que mais se aproximam do objetivo do nosso estudo: reconhecer e definir problemas, equacionar soluções, pensar estrategicamente, introduzir modificações no processo produtivo, atuar preventivamente, transferir e generalizar conhecimentos e exercer, em diferentes graus de complexidade, o processo da tomada de decisão; desenvolver expressão e comunicação compatíveis com o exercício profissional, inclusive nos processos de negociação e nas comunicações interpessoais ou intergrupais; ter iniciativa, criatividade, determinação, vontade política e administrativa, vontade de aprender, abertura às mudanças e consciência da qualidade e das implicações do seu exercício profissional.

Sempre que se fala em perfil, competências padrão, descrição do profissional, almeja-se o mais completo, e uma combinação perfeita seria a definida por Hersey e Blanchard (1986, p. 6), que afirmaram que para o "administrador executar com eficência sua profissão seria necessário que ele tivesse habilidades técnica, humana e conceitual, e isso faria dele o profissional ideal, almejado por qualquer organização". Uma outra classificação, segundo Berndt e Nagelschmidt (1995) é considerada bastante tradicional na literatura, mas também pode ser adotada como características para o profissional da Administração, abrangendo quatro habilidades básicas como atributos importantes: cognitiva (trabalhar informações), 
social (trabalhar pessoas), comunicação (trabalhar relacionamentos) e criatividade (trabalhar o pensar diferente).

A partir do entendimento do conceito de competência que mais se adequa ao contexto organizacional segundo Bergamini (201, p. 6) "É o recurso potencial que se tem para chegar ao desempenho de qualquer atividade no futuro. Sem ela não há desempenho (...)", e tendo em conta que competência valoriza mais os indivíduos que os resultados, programas, processos, políticas, equipamentos e recursos precisamos provocar a valorização dos indíviduos desde a sua formação, provocando mudanças de ação nos subsistemas organizacionais e no âmbito acadêmico, fazendo com que as instituições de ensino assumam novos conceitos de competência buscando melhorar a sua qualidade introduzindo no seu currículo e na sua orientação metodológica novas maneiras de aprendizagem que possibilitem o desenvolvimento de novas competências, que permitam uma formação profissional mais sólida e de mais fácil absorção pelo mercado de trabalho. Dentre essas mudanças que se impõem está a necessidade de se refletir sobre os aspectos comportamentais e emocionais do estudante do curso de administração tão prementes nesse seu processo. Poderemos afirmar que de acordo com Bergamini (2012, p. 26) "Gerir competências representa uma nova era da Administração de Empresas que se caracteriza, sobretudo, por promover um ambiente de atípica criatividade no sentido de que haja necessidade de substituir todos os recursos de um possível controle". Por outro lado trabalhar competências, exige um trabalho constante de autoaperfeiçoamento e, sobretudo, de aprendizagem, porque não dizer de desenvolvimento de inteligências a partir de estímulos como diria Gardner (1995). Partindo para uma aplicação do conhecimento, citamos Zarifian (1999) referido por Fleury e Fleury (2001, p. 187) quando afirmou que "a competência é a inteligência prática para situações que se apoiam sobre os conhecimentos adquiridos e os transformam com tanto mais força, quanto mais aumenta a complexidade das situações". Pois a prática daquela inteligência é o desenvolvimento daquela competência e vice versa. E embora a responsabilidade da prática não seja missão prioritária da universidade, as organizações, normalmente, esperam: que os indivíduos que obtiveram essa formação teórica sejam "competentes em tudo" para o atendimento da demanda do mercado de trabalho. Pois para as organizações competência como disseram Fleury e Fleury (2004, p. 48) "está, associada a verbos e expressões como: saber agir, mobilizar recursos, integrar saberes múltiplos e complexos, saber aprender, saber se engajar, assumir responsabilidades e ter visão estratégica"

A partir do estudo das competências no curso de administração e na tentativa de identificar formas mais exequíveis e produtivas de aprendizagem, passamos a incluir a Teoria das Inteligências Múltiplas (TIM) como uma prática interdisciplinar e também considerando que o sentido de ser inteligente ultrapassa a perspectiva do conceito da Psicologia para o que podemos justificar a partir do próprio Gardner (1995) quando afirmou que as teorias 
Um estudo sobre o perfil do administrador através da teoria das inteligências múltiplas em amostras pareadas

nem sempre são fieis às suas origens, assim como nem sempre antecipam seus destinos. Ele mesmo afirmou que acreditava que seu trabalho sobre a TIM interessaria principalmente àqueles treinados na sua disciplina, e particularmente àqueles que estudavam inteligência "mas havia uma outra audiência genuinamente interessada em minhas ideias - a audiência dos profissionais de educação, (...). Ela se amplia para o mundo dos professores universitários, pais e leigos instruídos" (Gardner, 1995, p. 4). O mesmo autor afirmou ainda que era necessário “(...) incluir um conjunto muito mais amplo e mais universal de competências do que comumente se considerou", e então definiu inteligência como "a capacidade de resolver problemas ou de criar produtos que sejam valorizados dentro de um ou mais cenários culturais" (Gardner,1995, p. 4).

Segundo a teoria de Gardner, resumidamente, as inteligências dividem-se em: Lógicomatemática - pessoas com essa inteligência mais proeminente desenvolvem mais facilmente habilidades em Matemática e em raciocínios lógico-dedutivos; Linguística pessoas com essa inteligência mais proeminente desenvolvem mais facilmente habilidades em escrita, leitura e em aprender idiomas; Espacial - pessoas com essa inteligência mais proeminente desenvolvem mais facilmente habilidades de lidar com objeto do concreto e sua realização; Corporal-Cinestésica - pessoas com essa inteligência mais proeminente desenvolvem mais facilmente habilidades para controlar os movimentos do corpo; Musical - pessoas com essa inteligência mais proeminente desenvolvem mais facilmente habilidades para perceber sons e criar sons e tocar instrumentos musicais;

Intrapessoal pessoas com essa inteligência mais proeminente desenvolvem mais facilmente habilidades para entender a si mesmo; Interpessoal - pessoas com essa inteligência mais proeminente desenvolvem mais facilmente habilidades em comunicar-se, entender o outro e relacionarse com ele; Natural - pessoas com essa inteligência mais proeminente desenvolvem mais facilmente habilidades em contemplar o desenvolvimento da natureza e suas formas; Existencial - pessoas com essa inteligência mais proeminente desenvolvem mais facilmente habilidades em refletir filosoficamente a vida e refletir a existência.

Sendo a Existencial considerada meia inteligênciaa visto ainda não ser reconhecida pela comunidade acadêmica e por sofrerem variações culturais e locais. As Intrapessoal e Interpessoal são consideradas as inteligências pessoais visto estarem diretamente ligadas ao desempenho humano e sua formação biopsicossocial.

O reconhecimento destas inteligências facilita processos de ensino mais individualizados, que ajudam o aluno a compreender os conteúdos nos quais tem mais dificuldade, a partir de sua inteligência mais desenvolvida. Enquanto em Antunes $(2012$, p.8) defende a "ideia de inteligência como unicidade e não utilizarmos o plural, inteligências, nada vai mudar".

Unimos as duas literaturas, sobre competência e inteligência, identificamos a possibilidade de usar a Teoria das IM na aprendizagem. Há uma infinidade de meios que podem ser 
usados além das várias inteligências que podem ser trabalhadas. Kornhaber e Krechevsky (apud Gardner, 1995) complementam definindo que inteligência é, principalmente, a manifestação de compromisso entre dois componentes: os indivíduos, que são capazes de utilizar sua série de competências em vários domínios de conhecimento, e as sociedades, que estimulam o desenvolvimento do indivíduo através das oportunidades que proporcionam, das instituições que sustentam e dos sistemas de valores que promovem.

\section{Metodologia}

O universo da pesquisa são os estudantes do curso de Administração de uma universidade publica do Estado do Ceará, Brasil, com matrículas ativas, dados do primeiro semestre de 2018 (matrículas semestrais) pois são realizados dois vestibulares no ano, distribuídos nos turnos diurno e noturno. $\mathrm{O}$ recorte da população foi feito em segmento, sendo o segmento representando o semestre. Havia o acesso ao objeto e contexto em estudo, permitindo recolherem-se os dados que subsidiaram a proposta da aplicação e comparação dos resultados da investigação no decorrer do tempo. Uma variável muito positiva foi a não evasão de nenhum aluno da amostra inicialmente trabalhada como também a não recusa da participação em responder o construto novamente. Podemos classificar a amostra como pareada. Foi a mesma amostra em número e em elementos amostrais trabalhada no início de 2015, quando estavam no semestre inicial do curso, e foram investigados também como elementos de parte da tese da autora, e agora na segunda metade de 2018, iniciando o último ano do curso, quantitativamente, e percentualmente bem maior a amostra visto ter a turma se reduzido. Os dados foram novamente recolhidos, por meio da aplicação do Inventário de Inteligências Múltiplas para Adultos (IMM), instrumento criado por Thomas Armstrong (2001) e adaptado do Teste de Inteligências Múltiplas de Howard Gardner. Esse constructo foi composto por 81 questões ordenadas por blocos correspondentes às inteligências pesquisadas, mas sem identificação da pergunta ao bloco na qual pertencia àquela inteligência. Não foram necessários grandes esclarecimentos sobre o construto (visto ser a mesma amostra e já ser conhecedora) mas sim sobre o novo objetivo, pois agora tratava-se de um estudo sobre a evolução das inteligências no decorrer do tempo do curso.

No que concerne ao tratamento e análise dos dados recolhidos foram privilegiados procedimentos estatísticos através da utilização do software estatístico SPSS (Statistical Package for the Social Science), utilizando também os dados da pesquisa anterior e fazendo um estudo comparativo antes-depois ou seja, amostras pareadas. Foi trabalhado, inicialmente com estatística descritiva, depois o teste de normalidade das variáveis dependentes que se trabalhou e suas correlações e significâncias, e por fim, a comparação dos dados e se analisou as diferenças. 
Um estudo sobre o perfil do administrador através da teoria das inteligências múltiplas em amostras pareadas

\section{Resultados e Considerações finais}

$\mathrm{Na}$ análise dos dados comparamos os resultados das oito inteligências: Linguística, Matemática, Espacial, Interpessoal, Motora, Musical, Intrapessoal, de uma amostra significativa, em torno de $30 \%$, considerando o semestre inicial como referência e quase $40 \%$ o semestre em curso como referência.

Gráfico 1. Faixa Etária por Género

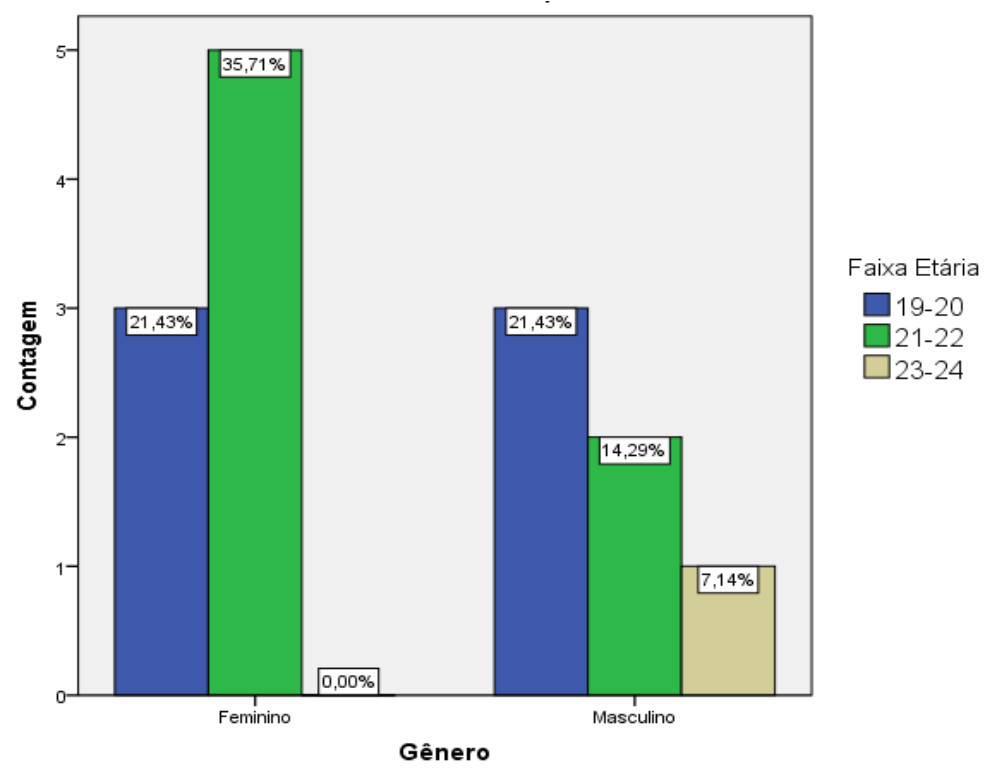

Todas as inteligências abordadas apresentam valores normalmente distribuídos na população, pois obtiveram níveis de significância superiores a 0,05 . Os valores de Sig. das inteligências são respectivamente: Linguística $(0,737)$, Matemática $(0,952)$, Espacial $(0,822)$, Interpessoal $(0,917)$, Motora $(0,859)$, Musical $(0,352)$ e Intrapessoal $(0,523)$. A partir desses dados foram feitos outros testes, iniciando pelo Qui-quadrado, na busca de identificar variáveis dependentes. O gênero não está associado ao desenvolvimento de nenhuma inteligência em específico, conforme comprovou o Teste do Qui-Quadrado. Todas as inteligências abordadas, ao confrontadas com o gênero dos respondentes apresentam frequências observadas e esperadas similares, pois obtiveram níveis de significância superiores a 0,05 , nesse caso, aceitando-se a hipótese da não associação. Os valores de Sig. dos testes das inteligências cruzadas com o gênero são respectivamente: Linguística $(0,335$, Matemática $(0,200)$, Espacial $(0,613)$, Intrapessoal $(0,161)$, Motora $(0,444)$, Musical $(0,409)$ e Interpessoal $(0,631)$. 
A idade também não se mostrou estar associada ao desenvolvimento de nenhuma das inteligências. Todas as inteligências abordadas, ao confrontadas com as faixas etárias informadas pelos respondentes apresentam frequências observadas e esperadas similares, pois obtiveram níveis de significância superiores a 0,05 . Ou seja, não foram identificados resultados consistentes que corroborem para a aceitação da associação entre as inteligências Linguística, Matemática, Espacial, Intrapessoal, Motora, Musical e Interpessoal com a variável Idade da amostra analisada. Os valores de Sig. dos testes das inteligências cruzadas com a idade são, respectivamente: Linguística $(0,184)$, Matemática $(0,297)$,Espacial $(0,368)$, Intrapessoal $(0,825)$, Motora $(0,304)$, Musical $(0,265)$ e Interpessoal $(0,264)$.

Analisando agora o desenvolvimento global das inteligências no decorrer do tempo, vemos que os níveis de significância para o Teste T de Amostras Pareadas foram superiores a 0,05 em todos os casos. Todas as inteligências abordadas não apresentaram diferenças nos valores de suas médias que fossem estatisticamente significativas, ou seja, estatisticamente não pôde ser percebido nenhum efeito de desenvolvimento em nenhuma das inteligências aplicadas na amostra participante do estudo.

\section{Gráfico 2. Médias das Inteligências Múltiplas}

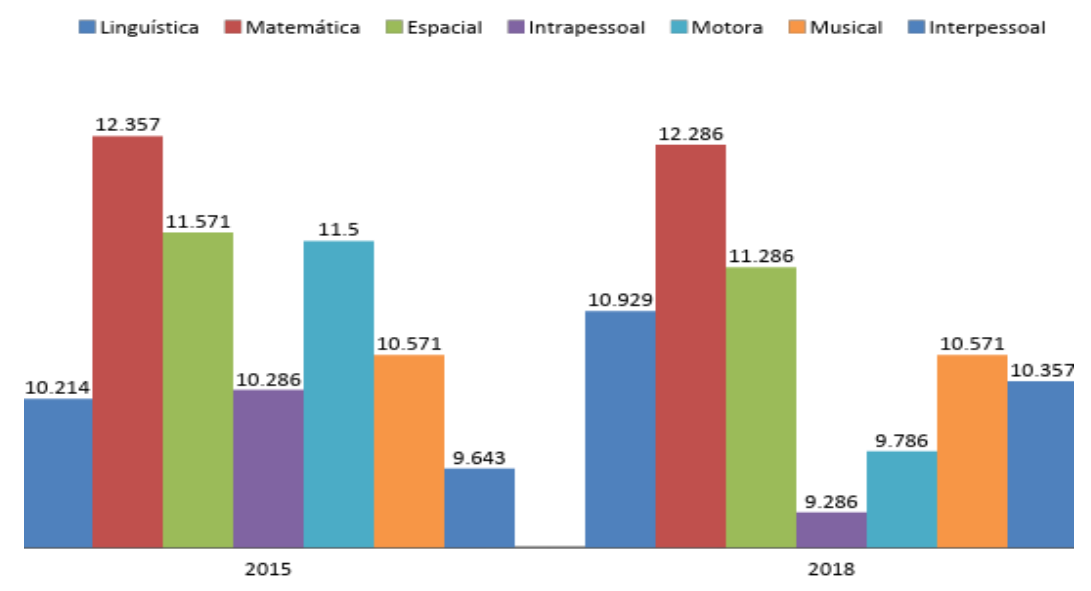

Dentro de um contexto geral, as inteligências definidas por Gardner não sofreram grandes evoluções no decorrem de um processo de aprendizagem considerado válido, foram cinco semestres considerados muito importantes para a formação do futuro profissional administrador. Segundo Bernt e Nagelschmidt (1995, p. 97) "O curso de administração pouco contribuiu para seu amadurecimento como seres humanos, embora tenha contribuído para os dotar de um instrumento de trabalho. Neste contexto, é importante lembrar que esse tipo de queixa (o curso não satisfaz o profissional no que ele almeja) pode ser justificado, já que a tendência em várias profissões é procurar pessoas capazes, autônomas, ou seja, profissionais competentes". As inteligências motora, espacial e musical realmente não tem 
Um estudo sobre o perfil do administrador através da teoria das inteligências múltiplas em amostras pareadas

grande representatividade para o profisssional em Administração, representam cultura geral e bem estar. A involução do desenvolvimento da inteligência matemática já é um pouco preocupante mas, em valores numéricos, foi de pouca representação, mas ponderamos que a tecnologia está a favor e mais importante que saber fazer o cálculo é fazer a leitura e análise daquele cálculo para a tomada de decisão. Mas é uma Inteligência muito importante dentro do instrumental da administração. Houve uma evolução na inteligência linguística, embora não se tenha níveis esperados que se possa comparar o volume e a representatividade dessa evolução, mas sabemos o quanto é importante para qualquer área do conhecimento o domínio da língua, da escrita e da fala.

Gráfico 3 e 4 . Evolução Inteligência Interpessoal/Intrapessoal

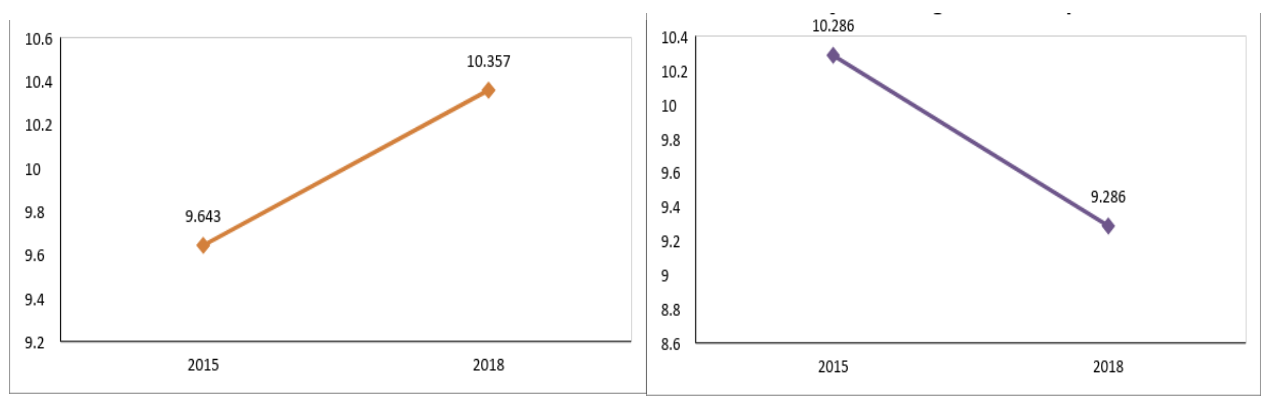

As inteligências pessoais, como assim chamou Gardner e apoiou Goleman, merecem todas as atenções dos estudantes de administração, visto serem as mais necessárias para esse profissional. A Interpessoal, que busca o desenvolvimento, a comunicação, o relacionamento e entendimento com o outro, teve um ganho bem positivo, resultado de ações de desenvolvimento de atividades extra sala, de extensão, de grupos de estudo, de empresa junior, de grupos de pesquisa e de trabalho, dentre outras, ações que podem facilmente terem continuidade. No entanto, a Intrapessoal, que busca o desenvolvimento e habilidades para entender a si mesmo, foi o inverso, o estudante de administração, deveria ter o sentido de melhorar o seu perfil, compreendendo a preocupação com valores morais, humanos, sociais, éticos, suas competências pessoais, dentre outros, e essa valoração deve ocorrer a todo momento a partir das informações e dos conhecimentos que lhe são apresentados no decorrer da vida acadêmica, o que não está ocorrendo, podendo ser em virtude, do envolvimento precoce com o trabalho, deficiência do método de aprendizagem da universidade, dentre outras questões, mas que no momento, não é o objetivo do estudo.

Temos que acreditar que, cada curso, de acordo com suas especificidades, define junto com seus atores a adequação do método, a sua forma de aprendizagem, como melhor aproveitar a experiência dos alunos na busca dos resultados esperados. Para se envolver ativamente no processo de aprendizagem, o aluno deve interagir a todo instante, seja lendo, escrevendo, perguntando, discutindo, resolvendo problemas, desenvolvendo projetos. Sendo assim, nos 
permitimos fazer algumas observações a partir do que foi observado com o resultado do estudo, ou seja, se faz necessário revisar as metodologias empregadas em sala de aula que podem auxiliar no desenvolvimento integral das inteligências. Tem havido constantes reformas na matriz curricular do curso no sentido de atualização do seu conteúdo mas a cultura discente ainda é muito tradicional, devemos adequar atividades extra sala à atividades curriculares com mais ênfase, com recursos multimídias, métodos ativos de aprendizagem e porque não trabalhar métodos de aprendizagem humanizada conforme apregoava Carl Rogers vinculando com os estudos de Gardner?

A reaplicação da pesquisa permitiu verificar o desenvolvimento das inteligências dos alunos, mas não necessariamente o crescimento esperado em todas elas no decorrer do curso e, paralelamente, consolidou a atuação da universidade como locus do saber, mantendo-se sempre que considerar a necessidade de melhoria contínua e da busca de novos métodos de aprendizagem.

\section{Referências}

Andrade, R. O. B., \& Amboni, N. (2004). Gestão de cursos de administração: metodologias e diretrizes curriculares. São Paulo: Prentice Hall.

Antunes, C. (2012). Jogos para estimulação das múltiplas inteligências. (20ª ed.) PetrópolisRJ: Vozes.

Armstrong, T. (2001). Inteligências múltiplas na sala de aula. (2. a ed). Porto Alegre. Artmed.

Berndt, A., \& Nagelschmidt, A. M. P. C. (1995). Atributos do administrador recémformado: um estudo de caso. Revista de Administração, São Paulo, 30(3), 91-97.

Bergamini, C. W. (2012). Competência: a chave do desempenho. São Paulo: Atlas.

Demo, P. (2009). Aprendizagens e novas tecnologias. Revista Brasileira de Docência, Ensino e Pesquisa em Educação Física, 1 (1), 53-75.

Fleury, M. T. L. \& Fleury, A. C. C. (2001). Construindo o conceito de competência. Revista de Administração Contemporânea - RAC, Edição Especial, 183-196.

Fleury, M. \& Fleury, A. (2004). Alinhando estratégia e competências. Revista de Administração de Empresas, 44(1), 44-57. doi:10.1590/S0034-75902004000100012

Gardner, H. (1995). Inteligências múltiplas. A Teoria na prática. (Maria Adriana V. Veronese, Trad.). Porto Alegre: Artmed.

Hersey, P., \& Blanchard, K. (1986). Psicologia para Administradores: a teoria e as técnicas da liderança situacional. São Paulo: EPU. 
Um estudo sobre o perfil do administrador através da teoria das inteligências múltiplas em amostras pareadas

Rosário, K. (2010). Um olhar sobre a importância de uma reflexão sobre as convergências e divergências entre o perfil dos egressos nos cursos superiores de administração e o perfil esperado pelo mercado de trabalho. Aampére: Faculade de Ampére.

Tavares Filho, J. P. \& Bernardes, J. F. (2005). Desafio das Universidades Empreendedoras: Universidade Tradicional x Universidade Corporativa. V Colóquio Internacional sobre Gestão Universitária na América do Sul. Disponível em:

http://repositório.ufsc.br/xmlui/handle/123456789/97426 